Sharif University of Technology
Scientia Iranica
SCIENTIA $\quad \begin{gathered}\text { Transactions D: Computer Science Es Engineering and Electrical Engineering } \\ \text { I RAN I C A }\end{gathered}$

Research Note

\title{
Voltage and reactive power control in a distribution network considering optimal network configuration and voltage security constraints
}

\author{
Gh. Memarzadeh and S. Esmaeili* \\ Department of Electrical Engineering, Shahid Bahonar University of Kerman, Kerman, Postal code: 7616914111, Iran.
}

Received 4 January 2017; received in revised form 6 February 2018; accepted 9 June 2018

\author{
KEYWORDS \\ Voltage and reactive \\ power control; \\ Distribution network \\ reconfiguration; \\ Distribution system; \\ Voltage security \\ constraints; \\ Non-dominated \\ Sorting Genetic \\ Algorithm-II \\ (NSGA-II).
}

\begin{abstract}
In order to reduce energy loss and improve voltage stability index in a distribution system, two different approaches, voltage and reactive power control (volt/var control) and distribution network reconfiguration, were proposed and employed. In the present paper, volt/var control and network reconfiguration in a distribution system considering voltage security constraints were modeled as a multi-objective optimization problem. Total electrical energy loss, voltage deviation, and voltage stability were considered as objectives. In addition, a new method for the distribution network reconfiguration was utilized to implement these two problems simultaneously. In this way, the two problems could be solved in a less amount of time. In addition, loads of different nature in each bus were considered in network load modeling. Non-dominated sorting genetic algorithm-II was used to solve this problem. Finally, the effectiveness of the proposed method was evaluated by its implementation on the IEEE 33-bus system and a real 77-bus distribution system.
\end{abstract}

(C) 2020 Sharif University of Technology. All rights reserved.

\section{Introduction}

Voltage and reactive power control and network reconfiguration are widely used to reduce power loss and improve voltage profile in distribution networks. In some studies, only voltage and reactive power control have been used for the effective operation of distribution networks (e.g., [1-15]). Meamarzadeh et al. proposed the volt/var control problem in a distribution system in the presence of distributed generators from a

*. Corresponding author. Tel.: +983431322500 E-mail addresses: reza.memarzadeh@eng.uk.ac.ir (Gh. Memarzadeh); s_esmaeili@uk.ac.ir (S. Esmaeili)

doi: $10.24200 /$ sci. 2018.20565 perspective of improving the voltage security index of the system [1]. Manbachi et al. presented an innovative smart grid-based volt-var optimization engine, capable of minimizing system power loss cost as well as the operating cost of switched capacitor banks while optimizing the system voltage using an improved Genetic Algorithm (GA) with two levels of mutation and two levels of crossover [2]. The proposed objectives include the total feeder loss, voltage profile, and limitation of reactive power flow into the main transformers. Besides, other researchers have studied this problem in the presence of distributed generation. Jashfar and Esmaeili presented volt/var/Total Harmonic Distortion (THD) control in distribution networks in the presence of the reactive power capability of solar energy conversion [3]. The main aim of this study is to 
find proper dispatch schedules for the capacitors, OnLoad Tap-Changer (OLTC) tap positions, and inverter reactive power of photovoltaic systems by considering the power quality constraints. Resener et al. presented an optimization model for volt/var control and energy loss minimization in power distribution networks, considering the presence of distributed generation [4]. Sayadi et al. presented a two-layer control method for voltage and reactive power control in a harmonic polluted distribution network with penetration of photovoltaic (PV) systems. Optimal scheduling of load tap changer and shunt capacitors for minimizing energy loss and improving the power quality simultaneously is performed using the Perturbation-Particle Swarm Optimization (P-PSO) method [5]. Niknam et al. proposed a stochastic multi-objective framework for daily volt/var control, including hydroturbine, fuel cell, wind turbine, and photovoltaic powerplants. For this purpose, the uncertainties related to hourly load, wind power, and solar irradiance forecasts are modeled in a scenario-based stochastic framework [6].

In addition to volt/var control, the distribution network reconfiguration is another significant control scheme in the distribution systems, which alters the topological structure of distribution feeders by changing open/closed status of sectionalizing and ties switches. After completing reconfiguration, the redial network that encompasses all buses is acceptable. The distribution network reconfiguration by considering all of the mentioned issues is a complicated nonlinear optimization problem. Distribution network reconfiguration has been studied by researchers [16-23]. Merlin and Back, for the first time in 1975, applied the idea of reconfiguration in the distribution network [16]. To implement the proposed method, first, all network switches are closed. Then, by applying the heuristic rules, each switch with less flow is opened. Civanlar et al. suggested a heuristic algorithm, where a simple formula was developed to determine changes in power loss due to a branch exchange [17]. Zhu proposed a refined GA for loss reduction in the distribution network [18]. Gupta et al. presented an efficient method based on GAs to improve the reliability and power quality of distribution systems using network reconfiguration [19]. Abazari and Heidari Soudejani presented an effective method to solve the reconfiguration problem of distribution systems so as to minimize the real power losses using the proposed new technique and the ant colony optimization [20]. Two new objective functions to address power quality and reliability issues in the reconfiguration problem are formulated in this study. Distribution network reconfiguration is also used along with other operation methods [21,22]. For example, Farahani et al. applied reconfiguration and capacitor placement simultan eously for energy loss reduction based on a simple branch exchange method of the single loop [21]. Zhao et al. proposed reactive power control of wind farm and network reconfiguration to obtain the optimal reactive power output of wind farm and network structure simultaneously by a joint optimization algorithm [22].

In the present study, to follow the previous work in [1], voltage and reactive power control and distribution network reconfiguration are studied simultaneously to obtain optimal dispatch schedules for OLTC settings and all shunt capacitors on the network and to determine the network structure, which is a novel viewpoint for the performance of distribution networks. For achieving this purpose, a new method is presented for distribution network reconfiguration in order to reduce the convergence time. In addition, the proposed volt/var control and network reconfiguration in distribution systems considering voltage security constraints can be modeled as a multi-objective optimization problem. The objective functions used in this problem include total electrical energy losses, voltage deviations, and Voltage Stability Index (VSI) that have been similarly used in [1]. However, in this paper, the non-dominated Sorting Genetic AlgorithmII (NSGA-II) is used instead of the old GA-based weighing method to find the global optimum solution more effectively. To illustrate the effectiveness of the proposed method, it is performed on IEEE 33-bus and real 77-bus distribution systems with loads of different nature in each bus. In addition, its performance is compared with that of the Multi-Objective Particle Swarm Optimization (MOPSO) algorithm. Simulation results show that the NSGA-II algorithm gives better performance than the other algorithm. The paper is outlined as follows: Section 2 presents the problem formulation. The method that is applied to the distribution network reconfiguration and volt/var control is introduced in Sections 3 and 4. Volt/var control and network reconfiguration in distribution systems utilized to save energy and improvement voltage stability are proposed in Section 5. Simulation results of the application of the suggested control scheme and the discussion about them are demonstrated in Section 6. Finally, major contributions and conclusions are summarized in Section 7.

\section{Problem formulation}

In this section, the objective function is presented; then, the governing constraints of this problem are introduced. This problem has been modeled as a multi-objective optimization problem. The objectives include (A) the minimization of the system's real power losses and the deviation of the bus voltage and (B) the maximization of VSI. The three objective functions are in contrast with each other, such that the improvement of voltage deviations reduces the VSI 
and increases power losses. On the other hand, the improvement of losses leads to an increase in the VSI, leading to an increase in voltage deviations. Thus, all of the three objective functions should be optimized simultaneously.

\subsection{Objective functions}

2.1.1. Minimization of the total electrical power losses The first objective function is the minimization of electrical energy losses that are expressed as follows [1]:

$$
f_{1}=\sum_{t=1}^{T} P_{l o s s, t},
$$

where $P_{\text {loss }, t}$ is the total system losses at time $t$, and $T$ is the total number of hours in a day.

\subsubsection{Minimization of the voltage deviations}

The voltage deviation of the distribution network for buses is expressed as follows [1]:

$$
\begin{gathered}
f_{2}=\frac{\sum_{t=1}^{T} U_{d}^{t}}{T}, \\
U_{d}^{t}=\sum_{i=1}^{N_{b u s}}\left|\frac{U_{i}^{N}-U_{i}^{t}}{U_{i}^{N}}\right|,
\end{gathered}
$$

where $U_{d}^{t}$ is the voltage deviation from the reference value, $U_{i}^{N}$ is the nominal voltage of bus $i$, and $U_{i}^{t}$ is the voltage magnitude of bus $i$.

\subsubsection{Maximization of the voltage stability}

The third objective function represents an indicator for assessing the voltage stability of the network, which is expressed by the following equations [1]. To achieve a good stability level of the network, this objective function must be maximized:

$$
\begin{aligned}
f_{3}= & \sum_{t=1}^{T} L_{t}, \\
L_{t}= & \min \left(S I_{1}, S I_{2}, \ldots, S I_{N b u s}\right), \\
S I_{j}= & \left\{\left|U_{i}\right|^{4}\right\}-4 \times\left\{P_{j} \times X(j j)-Q_{j} \times R(j j)\right\}^{2} \\
& -4 \times\left\{P_{j} \times R(j j)+Q_{j} \times X(j j)\right\} \times\left|U_{i}\right|^{2},
\end{aligned}
$$

where $P_{j}, Q_{j}$ are the active and reactive receiving end power, $U_{i}$ is the sending end voltage, $R(j j)+j X(j j)$ is the impedance of the line which is connected from bus $i$ to bus $j$, and Nbus is the maximum number of buses in the distribution system.

For stable operation of the system, SI must be greater than zero. Thus, each bus with the lowest index of stability $(S I)$ is closer to voltage collapse. By increasing the value of function $f_{3}$, the distribution network becomes more stable [24].

\subsection{Constraints}

Proper operating conditions of the network are achieved when the governing constraints of the network are satisfied initially; then, the objective functions will be optimized. Constraints of the volt/var control and distribution network reconfiguration problems are different. Therefore, in the first section, the constraints of the volt/var control problem are proposed; then, the constraints for distribution network reconfiguration will be investigated.

\subsubsection{Constraints of volt/var control problem}

The constraints of volt/var control problem are:

1. Magnitude of bus voltage:

$$
U_{\min }<U_{t, i}<U_{\max }
$$

where $U_{\min }$ and $U_{\max }$ are the minimum and maximum voltages in each bus, respectively;

2. Line flow limit:

$$
S_{T X, i} \leq S_{T X, r a t}
$$

where $S_{T X, i}$ is the apparent power flow on the substation transformer at time $i$, and $S_{T X, \text { rat }}$ is the substation transformer rating.

3. The daily number of OLTC operations limit:

$$
\sum_{t=1}^{T}\left|T A P_{t}-T A P_{t-1}\right| \leq T A P_{\max } .
$$

In Eq. (9), $T A P_{t}$ is the tap position of OLTC at time $t$, and $T A P_{\max }$ is the maximum switching operation for the OLTC;

4. Daily number of switching operations for shunt capacitors limit:

$$
\sum_{t=1}^{T}\left(C_{k, t} \oplus C_{K, t-1}\right)=C M_{k},
$$

where $C_{k, t}$ is the status of capacitor $k$ (on or off) at time $t, C M_{k}$ is the maximum switching operation for capacitor $k$, and $\oplus$ is the exclusive OR operation.

\subsubsection{Constraints of the distribution network reconfiguration problem}

The constraints of the distribution network reconfiguration problem are:

1. Magnitude of bus voltage:

$$
U_{\min }<U_{n}<U_{\max }
$$

where $U_{\min }$ and $U_{\max }$ are the minimum and maximum voltages in each bus, respectively; 
2. Line current for each line of the system:

$$
I_{n}<I_{n}^{\max } .
$$

Here, $I_{n}$ is the line capacity of the $n$th line, and $I_{n}^{\max }$ is the maximum capacity of the $n$th line of the distribution network;

3. After completing necessary reconfiguration, the network must be radial;

4. Lines current, voltage of buses, and all networking equipment must be in the permitted range;

5. The configured network must encompass all buses.

\section{Distribution network reconfiguration}

Distribution networks, which have the ability to perform reconfiguration, must have tie lines. If tie lines are closed, the network structure becomes ring-like. Therefore, to preserve the radial structure of the network, a number of tie lines must be opened. Therefore, the solution structure for the distribution network reconfiguration problem includes network switches that must be opened. The main point in this problem is the selection of switches that must be opened. In order to solve the distribution network reconfiguration problem properly, first, the governing constraints of the network must be satisfied; then, the objective functions should be optimized that have been used in the present study.

In the mentioned method, the following steps are considered:

1. The minimum number of distribution network rings is equal to the number of tie lines. For example, in a network with five tie lines, there must be at least five rings. Thus, in the first step of this method, the rings created by tie lines should be identified;

2. Some of the switches are shared between two or more rings. These switches must be identified and considered in one of the rings. By using this method, some of the rings in the network are converted to branches without a way back. Therefore, two constraints of the problem, including the radial structure of the distribution network and considering all buses of the network, are satisfied;
3. To allow the voltage of buses and lines current in the permitted range, the network configurations that have not met these constraints are removed by introducing penalty factors in power flow.

\section{Volt/var control in distribution system}

Volt/var control in the distribution network is a multiobjective optimization problem. To solve this problem, evolutionary algorithms can be used. In this paper, NSGA-II is used to solve the optimization problem. This algorithm is capable to find a global optimum solution, effectively. The structure of a feasible solution, which is considered in the present study, is shown in Figure 1. As is shown, the solution is composed of two parts. The first part is related to the capacitor 'on/off' switching modes, and the second part is related to the OLTC tap position.

\subsection{Time interval method considering the time-varying nature of loads}

In the distribution networks, a variety of loads, including residential, office, and commercial, utilize the network to supply their own needs. Of note, each of the loads in distribution systems with respect to network usage has its particular nature. Hence, in this study, loads of different nature are considered in the network. The contribution of each of the buses in the network from any nature of loads is specified. In order to determine the optimal load intervals, Eq. (13), as shown in Box I, has been used, where $M$ is the number of load intervals in a day, $K i$ is the number of hours at the $i$ th load interval, and $P_{R e s, i j}, Q_{R e s, i j}$, $P_{C o m, i j}, Q_{C o m, i j}, P_{O f f, i j}$, and $Q_{O f f, i j}$ are the active and reactive power of residential, commercial, and office load at the $j$ th load point of the $i$ th load interval, respectively. In addition, $P A_{\text {Res }, i}, Q A_{\text {Res }, i}, P A_{C o m, i}$, $Q A_{C o m, i}, P A_{O f f, i}$, and $Q A_{O f f, i}$ are the average active and reactive power of the residential load at the ith load interval, respectively. A GA is then employed to determine the beginning and the end of each interval.

\subsection{Dispatch of shunt capacitors}

At each hour, the improvement of power quality greatly depends on the location and size of the switched capacitors [10]. Furthermore, the continuous switching

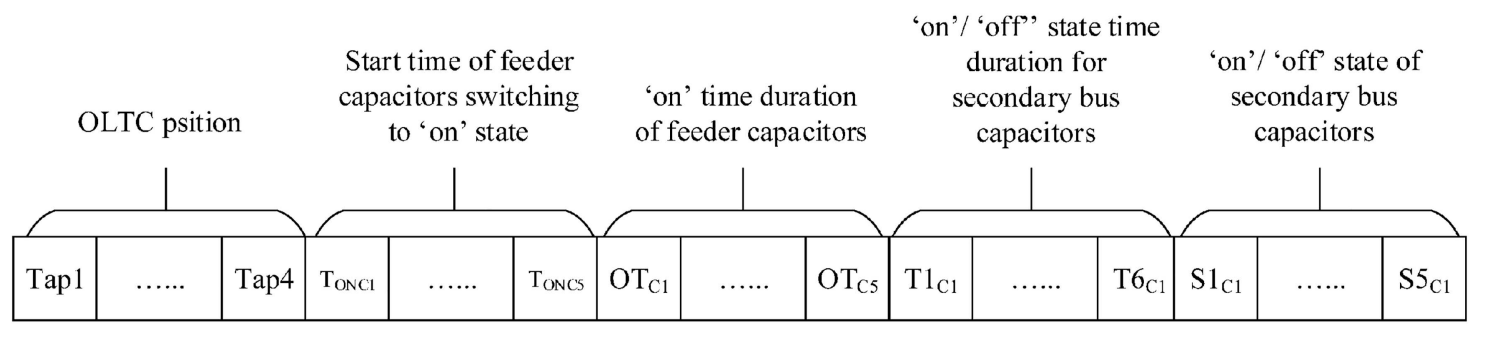

Figure 1. Solution structure of the voltage and reactive power control problem. 


$$
F=F_{\max }-\min \left(\begin{array}{c}
\sum_{i=1}^{M} \sum_{j=1}^{K_{i}}\left[\left(P_{\mathrm{Res}, i j}-P A_{\mathrm{Res}, i}\right)^{2}+\left(Q_{\mathrm{Res}, i j}-Q A_{\mathrm{Res}, i}\right)^{2}\right] \\
+\sum_{i=1}^{M} \sum_{j=1}^{K_{i}}\left[\left(P_{\mathrm{Com}, i j}-P A_{\mathrm{Com}, i}\right)^{2}+\left(Q_{\mathrm{Com}, i j}-Q A_{\mathrm{Com}, i}\right)^{2}\right] \\
+\sum_{i=1}^{M} \sum_{j=1}^{K_{i}}\left[\left(P_{\mathrm{Off}, i j}-P A_{\mathrm{Off}, i}\right)^{2}+\left(Q_{\mathrm{Off}, i j}-Q A_{\mathrm{Off}, i}\right)^{2}\right]
\end{array}\right)
$$

\section{Box I}

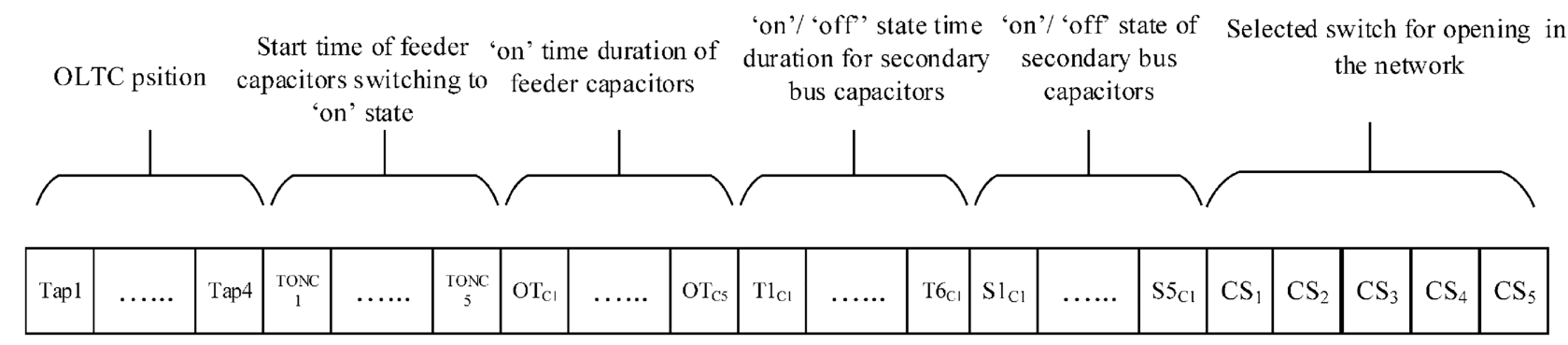

Figure 2. Solution structure of the voltage and reactive power control in the distribution network considering optimal network configuration problem.

of capacitor banks will reduce their lifetime. In this paper, a method is utilized to guarantee the suppression of maximum allowable daily capacitors along a feeder and a substation's capacitor switching, effectively correcting the convergence process.

\subsubsection{Capacitors along feeder}

These capacitors are normally allowed to be switched 'on' and 'off' once a day. Therefore, each capacitor occupies two segments in the genome. The first segment represents the time at which the capacitor is switched on, while the second one represents the time duration in which the capacitor remains on. For example, assume that the initial state of the capacitor is off and the first and second variables in the genome are 4 and 9 , respectively. Thus, it is implied that the capacitor will be switched on at 4:00 and switched off at 13:00.

\subsubsection{Substation's capacitor}

Considering the limitation of capacitors daily operation, these capacitors should be programmed in a way that the constraints in switching capacitors become implicit $[3,25]$. This programming procedure has appropriate convergence. However, it requires large computational volume. If the maximum number of switching operations for substation's capacitor is considered 6 , by using this method, 24 hours per day should be divided into six parts. Then, the minimum and maximum amounts of time intervals are considered to be 0 and 4 , respectively.

\section{Volt/var control and network reconfiguration in the distribution system}

In this paper, volt/var control and network reconfiguration in the distribution system are employed to reduce energy loss and improve VSI. The state variable vector is $X=[V V C, R E C] . \quad V V C$ is variable, which represents the voltage and reactive power control. $R E C$ is variable, which represents the status of switches in the distribution network. Figure 2 represents a solution structure of the volt/var control and network reconfiguration in the distribution system, which is solved by NSGA-II. The stopping criterion of the algorithm is the maximum number of iterations. A schematic diagram of the computational procedure is shown in Figure 3.

\section{Simulation results and discussion}

In this paper, to demonstrate the performance of the proposed optimization algorithm, the five following cases are studied:

- Case1: Original network without any action;

- Case 2: Only performing distribution network reconfiguration;

- Case 3: Only performing voltage and reactive power control in the distribution network;

- Case 4: First performing the distribution network reconfiguration and, then, performing voltage and reactive power control; 


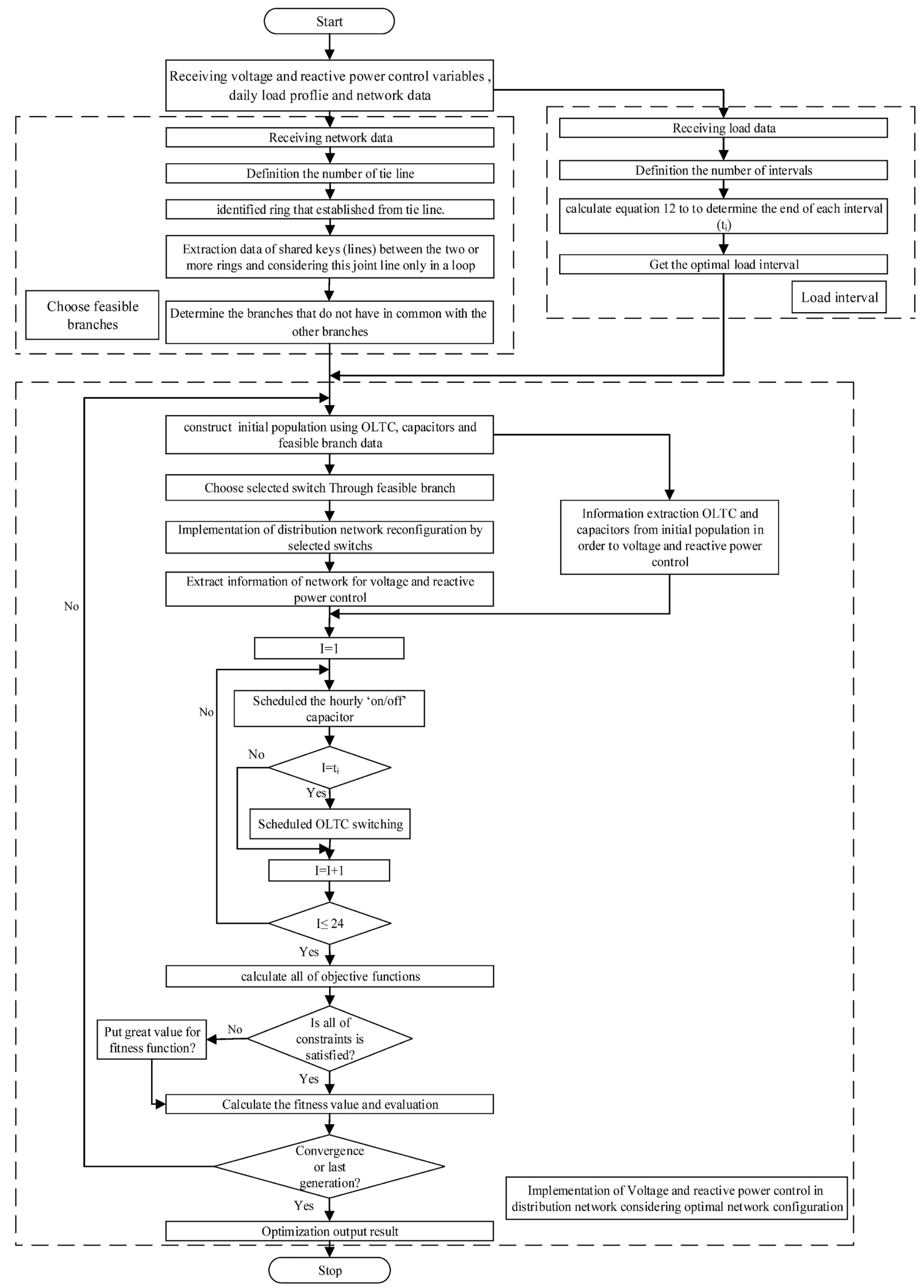

Figure 3. Flowchart of the proposed voltage and reactive power control in the distribution network considering optimal network configuration. 
Table 1. Capacitor data for the IEEE 33-bus distribution system.

\begin{tabular}{ccccccc}
\hline Capacitor number & $C_{1}$ & $C_{2}$ & $C_{3}$ & $C_{4}$ & $C_{5}$ & $C_{6}$ \\
\hline Capacity (kVAr) & 350 & 200 & 100 & 200 & 200 & 350 \\
Location & 1 & 8 & 14 & 24 & 25 & 30 \\
\hline
\end{tabular}

- Case 5: Performing volt/var control and network reconfiguration in the distribution system.

\subsection{IEEE 33-bus distribution system}

Figure 4 shows the test system with capacitors installed on buses 1, 8, 14, 24, 25, and 30. The detailed data of the capacitors are described in Table 1 . The OLTC has 17 tap positions $([-8 \ldots 0 \ldots 8])$ and is able to change the voltage level from 0.95 to 1.05 per unit. The voltage on the primary bus of a substation is 1.0 per unit.

Loads of different nature considered in the network are shown in Figure 5. Figure 6 shows the contribution of each of the buses in the network from any nature of the load. For these load profiles, the number of intervals $(M)$ is considered 4. Information about the parameters of the algorithm is given in Table 2 .

For comparison purposes, the NSGA-II and MOPSO algorithms have been applied to the IEEE 33bus distribution system with the same conditions and system data. The results of the simulation for these cases are provided in Table 3.

Table 2. Optimization parameters used in the dispatch problem.

\begin{tabular}{cc}
\hline Parameter & Value \\
\hline Maximum generation & 200 \\
Population size & 100 \\
Probability of crossover & 0.7 \\
Probability of mutation & 0.3 \\
Mutation rate & 0.0025 \\
\hline
\end{tabular}
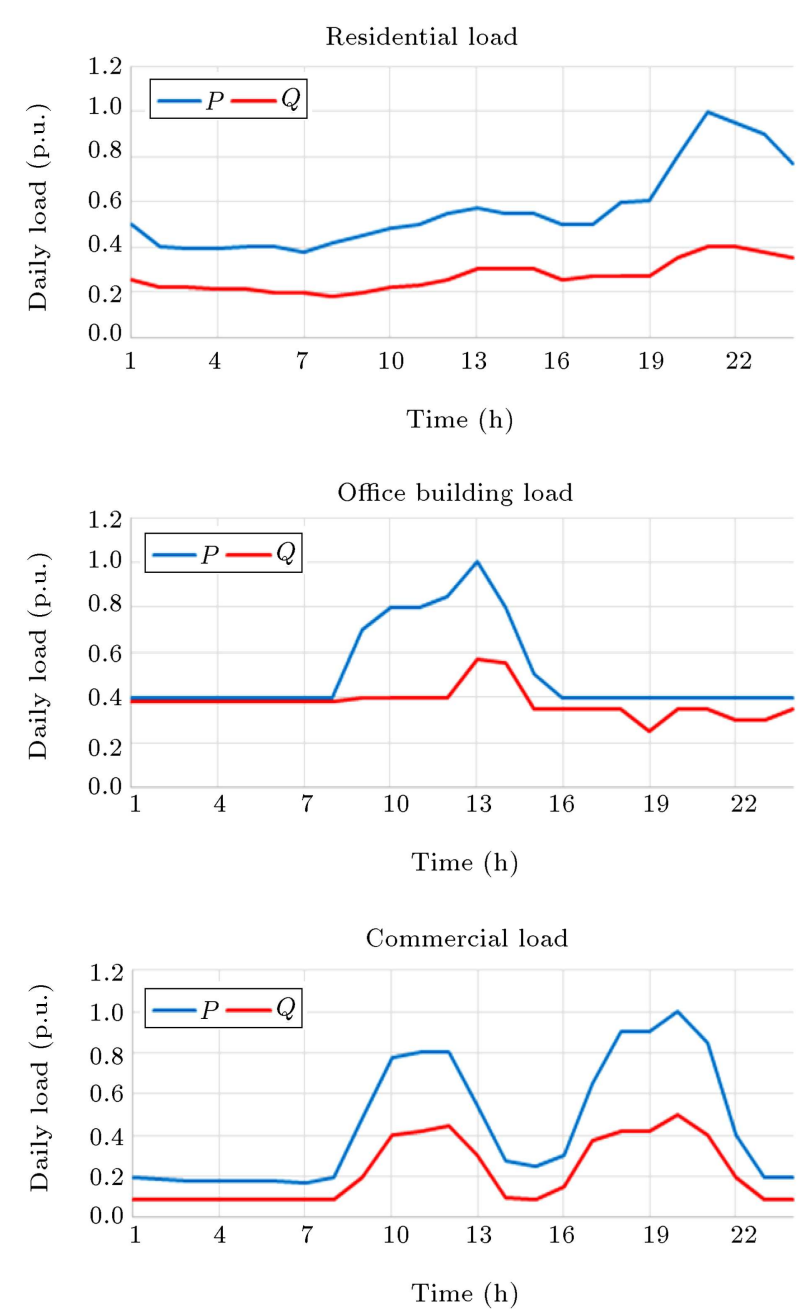

Figure 5. Different nature of loads considered in the network.

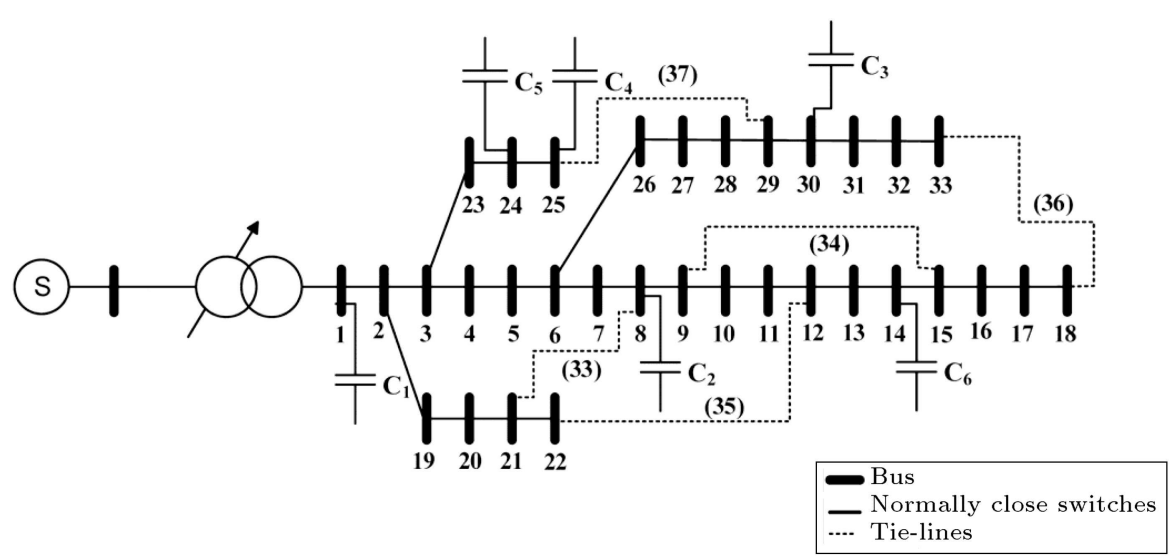

Figure 4. One-line diagram of the IEEE 33-bus distribution system. 
Table 3. Results of the proposed cases in the IEEE 33-bus test system.

\begin{tabular}{|c|c|c|c|c|c|}
\hline Case & $\begin{array}{l}\text { Optimization } \\
\text { algorithm }\end{array}$ & $\begin{array}{c}\text { Power losses } \\
(\mathrm{kW})\end{array}$ & $\begin{array}{c}\text { Voltage deviation } \\
\text { (p.u.) }\end{array}$ & $\begin{array}{l}\text { Voltage stability } \\
\text { index (p.u.) }\end{array}$ & $\begin{array}{c}\text { Open } \\
\text { switches }\end{array}$ \\
\hline \multirow{2}{*}{1} & NSGA-II & 1.0023 & 0.7161 & 19.0491 & $33,34,35,36,37^{*}$ \\
\hline & MOPSO & 1.0023 & 0.7161 & 19.0491 & $33,34,35,36,37^{*}$ \\
\hline \multirow{2}{*}{2} & NSGA-II & 0.6972 & 0.4850 & 20.5166 & $7,9,14,32,33$ \\
\hline & MOPSO & 1.2040 & 0.6114 & 19.3791 & $9,14,28,32,34$ \\
\hline \multirow{2}{*}{3} & NSGA-II & 0.8691 & 0.4083 & 23.6000 & $33,34,35,36,37^{*}$ \\
\hline & MOPSO & 0.8801 & 0.4630 & 23.5543 & $33,34,35,36,37^{*}$ \\
\hline \multirow{2}{*}{4} & NSGA-II & 0.6586 & 0.3995 & 24.3231 & $7,9,14,32,33$ \\
\hline & MOPSO & 0.7443 & 0.5466 & 23.8911 & $9,14,28,32,34$ \\
\hline \multirow{2}{*}{5} & NSGA-II & 0.6428 & 0.3943 & 24.3364 & $7,9,14,28,33$ \\
\hline & MOPSO & 0.6777 & 0.4881 & 23.9906 & $10,26,32,34,36$ \\
\hline
\end{tabular}

${ }^{*}$ The initial state of the network switches.

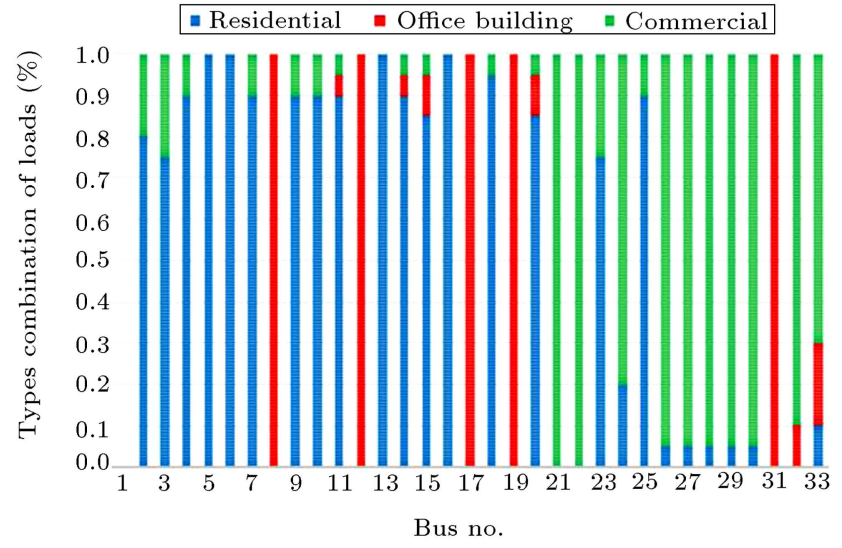

Figure 6. Contribution of each of the buses in the network from any nature of load.

In this network, before implementing any network optimization process, including voltage and reactive power control and distribution network reconfiguration, buses 18 and 33 have the lowest voltage and VSI. Therefore, the voltage and VSI for all cases are shown in Figures 7 and 8 . A summary of voltage, VSI, and energy saving in the system with different cases is visible in Table 4.

\subsection{Real 77-bus distribution network}

The proposed algorithm is tested on two feeders of a real 77-bus distribution network of the city of Sirjan in Iran (see Figure 9), and satisfactory results are obtained. Capacitors of this network are installed on buses $10,21,33,43,56,67$, and 74 . The detailed data
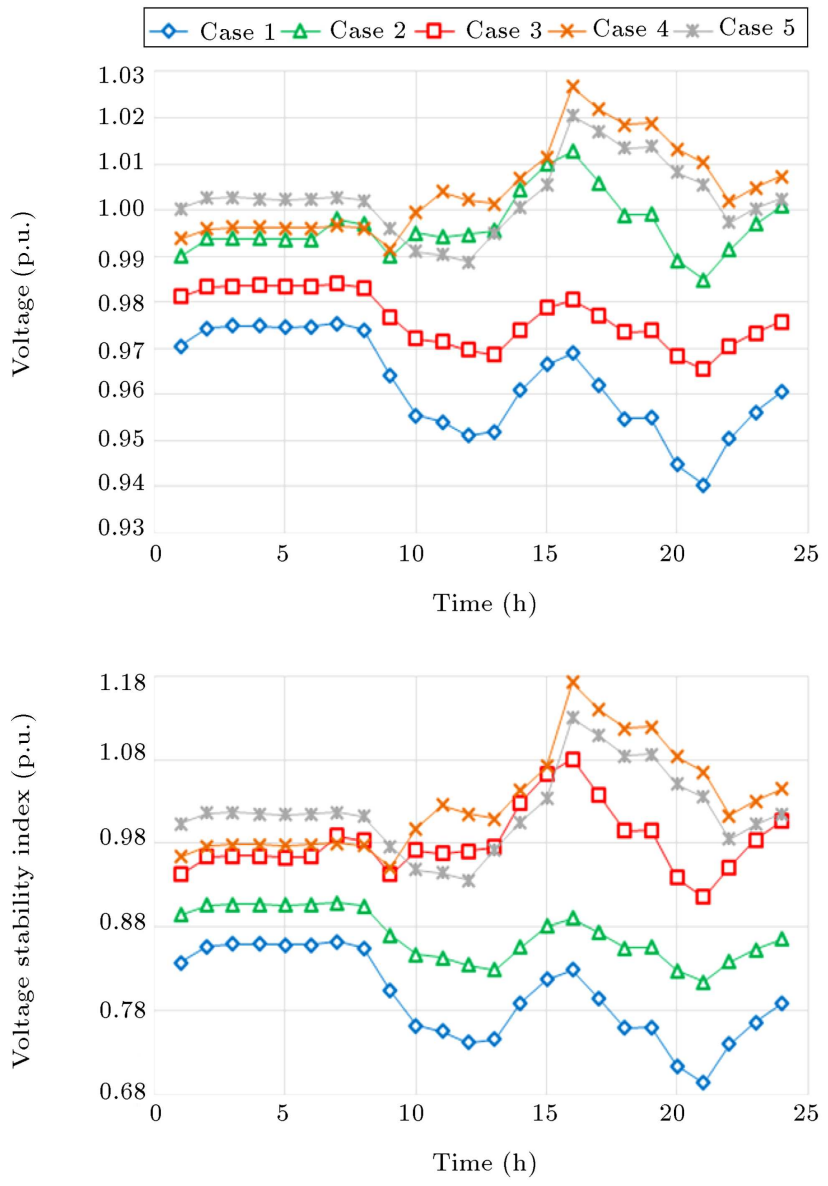

Figure 7. Voltage and voltage stability index improvement of bus 18 . 
Table 4. Summary results of approaches.

\begin{tabular}{cccccccc}
\hline Case & $\begin{array}{c}\text { Power } \\
\text { saving } \\
(\boldsymbol{\%})\end{array}$ & $\begin{array}{c}\text { Average } \\
\text { system } \\
\text { voltage (p.u.) }\end{array}$ & $\begin{array}{c}\text { Maximum } \\
\text { voltage } \\
\text { (p.u.) }\end{array}$ & $\begin{array}{c}\text { Minimum } \\
\text { voltage } \\
\text { (p.u.) }\end{array}$ & $\begin{array}{c}\text { Average } \\
\text { system VSI } \\
\text { (p.u.) }\end{array}$ & $\begin{array}{c}\text { Maximum } \\
\text { VSI (p.u.) }\end{array}$ & $\begin{array}{c}\text { Minimum } \\
\text { VSI (p.u.) }\end{array}$ \\
\hline $\mathbf{2}$ & 30.44 & 0.9860 & 1 & 0.9595 & 0.9211 & 1 & 0.9595 \\
$\mathbf{3}$ & 13.29 & 1.0098 & 1.0327 & 0.9849 & 1.0630 & 1.0327 & 0.9849 \\
$\mathbf{4}$ & 34.3 & 1.0104 & 1.0329 & 0.9881 & 1.0693 & 1.2110 & 0.9358 \\
$\mathbf{5}$ & 35.87 & 1.0109 & 1.0329 & 0.9886 & 1.0698 & 1.2560 & 0.9509 \\
\hline
\end{tabular}

Table 5. Capacitor data for real 77-bus distribution system.

\begin{tabular}{cccccccc}
\hline & \multicolumn{8}{c}{ Capacitor number } \\
\cline { 2 - 8 } & $\boldsymbol{C}_{\mathbf{1}}$ & $\boldsymbol{C}_{\mathbf{2}}$ & $\boldsymbol{C}_{\mathbf{3}}$ & $\boldsymbol{C}_{\mathbf{4}}$ & $\boldsymbol{C}_{\mathbf{5}}$ & $\boldsymbol{C}_{\mathbf{6}}$ & $\boldsymbol{C}_{\mathbf{7}}$ \\
\cline { 2 - 8 } Capacity (kVAr) & 545 & 625 & 625 & 420 & 545 & 515 & 265 \\
Location & 10 & 21 & 33 & 43 & 56 & 67 & 74 \\
\hline
\end{tabular}
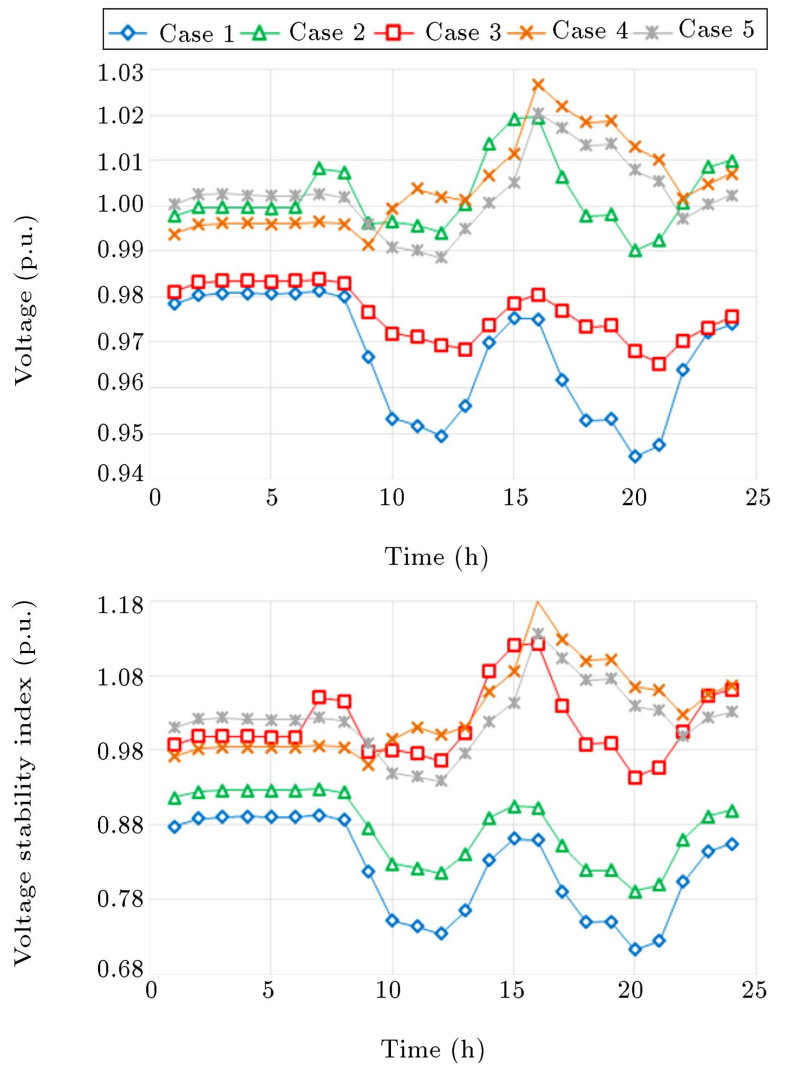

Figure 8. Voltage and voltage stability index improvement of bus 33 .

of the capacitors are described in Table 5. This system has 114 sectionalizing branches and 10 tie branches called Line1, Line $2, \ldots$, Line10. The line data and power of loads at the time of peak load of this network are presented in [21]. The OLTC has 17 tap positions $([-8 \ldots 0 \ldots 8])$ and is able to change the voltage level from 0.95 to 1.05 per unit. Figure 10 shows the contribution of each of the buses in the network from any nature of loads. Information about the parameters of the algorithm for this system is the same as that of the previous test case. The results of the cases obtained using the two procedures are presented in Table 6; the results confirm the effectiveness of the proposed method. A summary of voltage, VSI, and energy saving in the system with different cases (Cases 2-5) is shown in Table 7 . These results represent the advantage of each of Cases 2 to 5 in each of the indicators.

\subsection{Discussion of results}

Based on the results of the previous sections, although the energy losses in Case 2 have improved appropriately, the VSI and voltage deviations have not significantly improved. Similarly, in Case 3, there is an improvement in indicators related to bus voltages; however, no significant improvement in energy losses is observed. The results listed in Tables $3,4,6$, and 7 confirm this fact. By implementing Cases 4 and 5 , both energy losses and voltage indicators have improved. Figures 7 and 8 show that the voltage profiles of buses 18 and 33 of IEEE 33 bus test system have improved to their allowable value in Cases 4 and 5. Furthermore, Figures 7 and 8 show that the VSI of buses 18 and 33 has improved in these cases. In Case 2 , by changing the configuration of the network, energy losses are reduced; however, due to the lack of OLTC and capacitors operations, there is no possibility to control reactive power and improve voltage profiles. In Case 3, by 


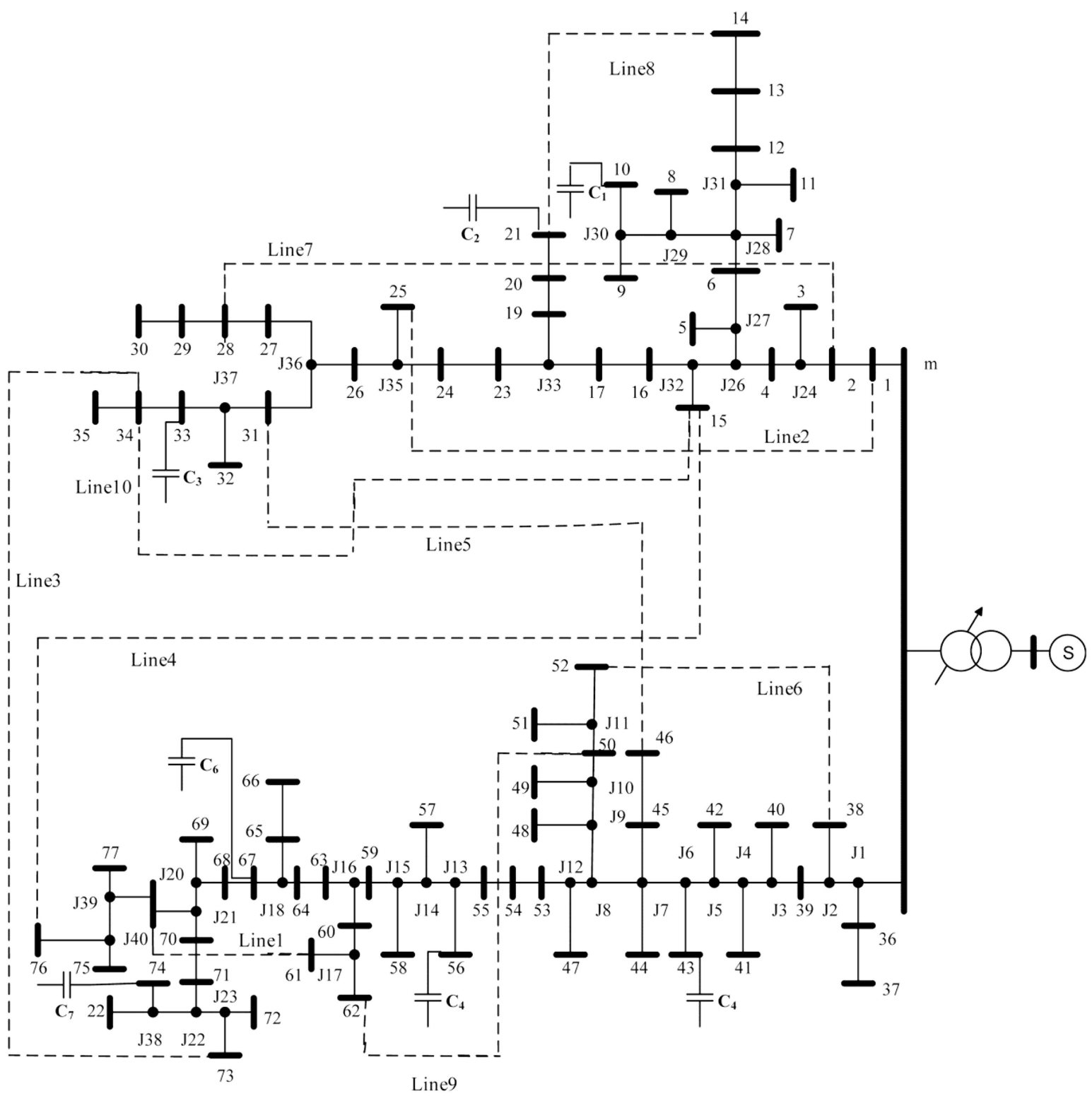

Bus

- Normally close switches Tie-lines

Figure 9. Real 77-bus distribution system.

using the OLTC of the transformer and capacitors, all voltage specifications have improved. However, the network configuration is not optimum, and energy loss is not appropriate. The number of the total OLTC and capacitors' switching operations per day satisfies the constraints. The results show that the capacitor's switching and daily load curves are dependent. In other words, considering the daily load curve, the capacitors prevent unnecessary switching.

\section{Conclusion}

The secure and economic operation of power systems is of immense importance. Voltage and reactive power control and distribution network reconfiguration were used to improve these conditions in the distribution network. Thus, in this paper, volt/var control and network reconfiguration in the distribution system and voltage security constraints were proposed to improve network security and economic limitations. This problem was modeled as a multi-objective optimization problem. The objectives studied in this paper included total electrical energy losses, voltage's deviations, and voltage stability. NSGA-II was used to solve the optimization problem. The results by using the proposed method were compared to those reported in 
Table 6. Results of the proposed cases in the real 77-bus distribution system.

\begin{tabular}{|c|c|c|c|c|c|}
\hline Case & $\begin{array}{l}\text { Optimization } \\
\text { algorithm }\end{array}$ & $\begin{array}{c}\text { Power } \\
\text { losses } \\
(\mathrm{kW})\end{array}$ & $\begin{array}{c}\text { Voltage } \\
\text { deviation } \\
\text { (p.u.) }\end{array}$ & $\begin{array}{c}\text { Voltage } \\
\text { stability } \\
\text { index (p.u.) }\end{array}$ & $\begin{array}{c}\text { Open } \\
\text { switches }\end{array}$ \\
\hline \multirow{2}{*}{1} & NSGA-II & 0.1095 & 0.3546 & 23.4845 & Line1, Line2,..., Line10 \\
\hline & MOPSO & 0.1095 & 0.3546 & 23.4845 & Line1, Line2,..., Line10 \\
\hline \multirow[t]{2}{*}{2} & NSGA-II & 0.0858 & 0.3162 & 23.5710 & $\begin{array}{c}\text { 13-14, 17-J33, J36-27, J8-J9, 59-J16, } \\
\text { J17-62, 63-64, 70-J39, 31-46, 15-36 }\end{array}$ \\
\hline & MOPSO & 0.0864 & 0.3169 & 23.5725 & $\begin{array}{l}\text { 13-14, 20-21, J36-27, J8-J9, 59-J16, } \\
\text { J17-62, 63-64, 70-J39, 31-46, 15-36 }\end{array}$ \\
\hline \multirow{2}{*}{3} & NSGA-II & 0.1014 & 0.3435 & 24.0919 & Line1, Line2,..., Line10 \\
\hline & MOPSO & 0.1018 & 1.7634 & 23.7191 & Line1, Line2,..., Line10 \\
\hline \multirow[t]{2}{*}{4} & NSGA-II & 0.0802 & 0.3476 & 24.1851 & $\begin{array}{c}\text { 13-14, 17-J33, J36-27, J8-J9, 59-J16, } \\
\text { J17-62, 63-64, 70-J39, 31-46, 15-36 }\end{array}$ \\
\hline & MOPSO & 0.0984 & 1.6519 & 23.7903 & $\begin{array}{l}\text { 13-14, 20-21, J36-27, J8-J9, 59-J16, } \\
\text { J17-62, 63-64, 70-J39, 31-46, 15-36 }\end{array}$ \\
\hline \multirow[t]{2}{*}{5} & NSGA-II & 0.0791 & 0.6086 & 24.3152 & $\begin{array}{l}\text { J31-11, J33-23, J36-27, J8-J9, 59-J16, } \\
\text { J17-62, J18-67, J39-J40, 41-64, 25-45 }\end{array}$ \\
\hline & MOPSO & 0.0961 & 2.4477 & 23.9979 & $\begin{array}{c}12-13,24-\mathrm{J} 53, \mathrm{~J} 7-\mathrm{J} 8, \mathrm{~J} 16-60, \mathrm{~J} 17-62, \\
15-76,31-46,38-52,2-28,15-36\end{array}$ \\
\hline
\end{tabular}

Table 7. Summary results of approaches.

\begin{tabular}{cccccccc}
\hline Case & $\begin{array}{c}\text { Power saving } \\
(\mathbf{\%})\end{array}$ & $\begin{array}{c}\text { Average } \\
\text { system } \\
\text { voltage }(\mathbf{p . u .})\end{array}$ & $\begin{array}{c}\text { Maximum } \\
\text { voltage } \\
(\mathbf{p . u .})\end{array}$ & $\begin{array}{c}\text { Minimum } \\
\text { voltage } \\
(\mathbf{p . u .})\end{array}$ & $\begin{array}{c}\text { Average } \\
\text { system VSI } \\
(\mathbf{p . u .})\end{array}$ & $\begin{array}{c}\text { Maximum } \\
\text { VSI } \\
(\mathbf{p . u .})\end{array}$ & $\begin{array}{c}\text { Minimum } \\
\text { VSI } \\
(\mathbf{p . u .})\end{array}$ \\
\hline $\mathbf{2}$ & 21.64 & 0.9973 & 1 & 0.9952 & 0.9837 & 0.9717 & 0.9940 \\
$\mathbf{3}$ & 7.4 & 1.0015 & 1.0079 & 0.9973 & 1.0096 & 1.0484 & 0.9841 \\
$\mathbf{4}$ & 26.76 & 1.0019 & 1.0081 & 0.9978 & 1.0115 & 1.0494 & 0.9867 \\
$\mathbf{5}$ & 27.76 & 1.0038 & 1.0200 & 0.9977 & 1.0241 & 1.1263 & 0.9865 \\
\hline
\end{tabular}

the literature. The results confirmed the potential of the proposed approach and showed its effectiveness and superiority over the MOPSO algorithm. The results obtained by the simulations showed that network reconfiguration and volt/var control could reduce energy losses and improve voltage stability. However, the best solution for these two objective functions did not occur separately. Hence, these two problems should be considered simultaneously. Following the implementation of volt/var control and network reconfiguration in the distribution system, all objective functions improved. Considering the daily nature of the load curve, the capacitors prevented unnecessary switching. 


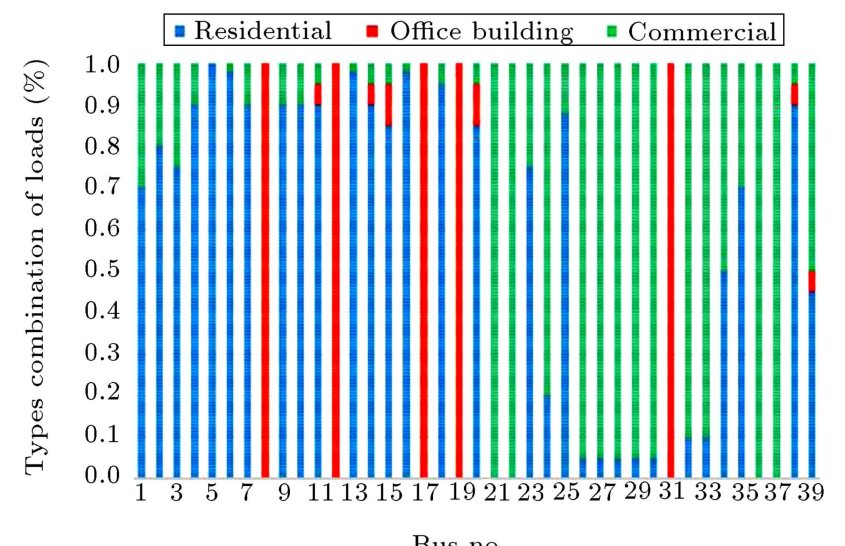

Bus no.

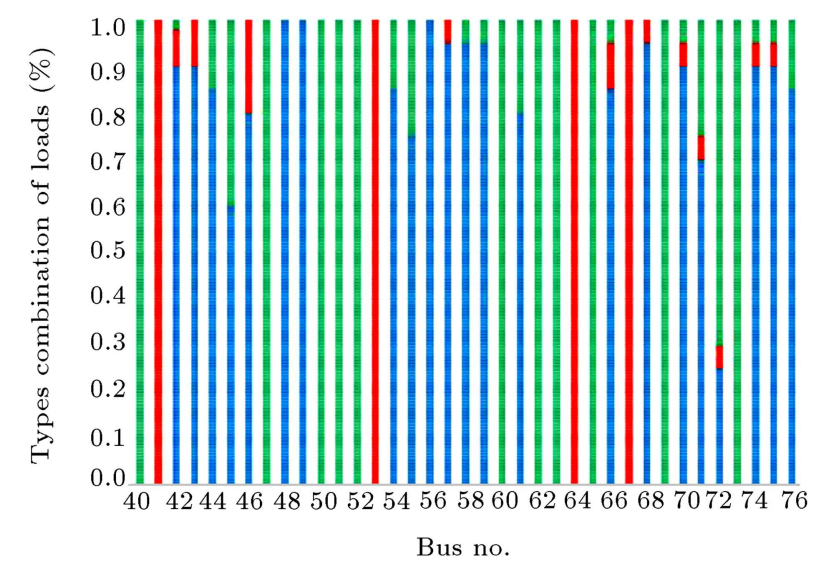

Figure 10. Contributions of buses 1 to 77 of real 77 -bus distribution system from any nature of loads.

\section{References}

1. Meamarzadeh, Gh., Esmaeili, S., and Mohamadi Abdar, H. "Daily volt/var control in distribution system in presence of distributed generators considering voltage security constraints", 50th AIAA/ASME/SAE/ASEE Joint Propulsion Conference, Cleveland, Ohio, USA, pp. 59-68 (2014).

2. Manbachi, M., Farhangi, H., Palizban, A., and Arzanpour, S. "A novel volt-var optimization engine for smart distribution networks utilizing vehicle to grid dispatch", Int J Elec Power, 74, pp. 238-251 (2016).

3. Jashfar, S. and Esmaeili, S. "Volt/var/THD control in distribution networks considering reactive power capability of solar energy conversion", Int $J$ Elec Power, 60(1), pp. 221-233 (2014).

4. Resener, M., Haffner, S., Pereira, L., et al. "Mixedinteger LP model for volt/var control and energy losses minimization in distribution systems", Electr Pow Syst Res, 140(1), pp. 895-905 (2016).

5. Sayadi, F., Esmaeili, S., and Keynia, F. "Two-layer volt/var/total harmonic distortion control in distribution network based on PVs output and load forecast errors", IET Gener Transm Dis, 11(8), pp. 2130-2137 (2016).

6. Niknam, T., Zare, M., and Aghaei, J. "Scenario- based multiobjective volt/var control in distribution networks including renewable energy sources", IEEE T Power Deliver, 27(4), pp. 2004-2019 (2012).

7. Niknam, T., Bahmani Firouzi, B., and Ostadi, A. "A new fuzzy adaptive particle swarm optimization for daily volt/var control in distribution networks considering distributed generators", Appl Energ, 87(6), pp. 1919-1928 (2010).

8. Zare, M. and Niknam, T. "A new multi-objective for environmental and economic management of volt/var control considering renewable energy resources", Energy, 55(1), pp. 236-252 (2013).

9. Azimi, R. and Esmaeili, S. "Multi-objective daily volt/var control in distribution systems with distributed generation using binary ant colony optimization", Turk J Electr Eng Co, 21(3), pp. 613-629 (2013).

10. Liang, R.H., Chen, Y.K., and Chen, Y.T. "Volt/var control in a distribution system by a fuzzy optimization approach", Int J Elec Power, 33(2), pp. 278-287 (2011).

11. Ulinuha, A., Masoum, M.A.S., and Islam, S. "Hybrid genetic-fuzzy algorithm for volt/var/total harmonic distortion control of distribution systems with high penetration of non-linear loads", IET Gener Transm Dis, 5(4), pp. 425-439 (2011).

12. Niknam, T. "A new HBMO algorithm for multiobjective daily volt/var control in distribution systems considering distributed generators", Appl Energ, 88(3), pp. $778-788$ (2011).

13. Tushar, M.H.K. and Assi, CH. "Volt-var control through joint optimization of capacitor bank switching, renewable energy, and home appliances", IEEE Trans. Smart Grid, 9(5), pp. 4077-4086 (2017).

14. Sabillon-Antunez, C.F., Melgar-Dominguez, O.D., Franco, J.F., et al. "Volt-var control and energy storage device operation to improve the electric vehicle charging coordination in unbalanced distribution networks", IEEE Trans. Sustain. Energy, 8(4), pp. 15601570 (2017).

15. Malekpour, A.R., Tabatabaei, S., and Niknam, T. "Probabilistic approach to multi-objective volt/var control of distribution system considering hybrid fuel cell and wind energy sources using improved shuffled frog leaping algorithm", Renew Energ, 39(1), pp. 228240 (2012).

16. Merlin, A. and Back, H. "Search for a minimumloss operating spanning tree configuration for an urban power distribution system", Proc. Power Systems Comp. Conf., Cambridge, UK, pp. 1-5 (1975).

17. Civanlar, S., Grainger, J.J., Yin, H., et al. "Distribution feeder reconfiguration for loss reduction", IEEE T Power Deliver, 3(3), pp. 1217-1223 (1988). 
18. Zhu, J.Z. "Optimal reconfiguration of electrical distribution network using the refined genetic algorithm", Electr Pow Syst Res, 62(1), pp. 37-42 (2002).

19. Gupta, N., Swarnkar, A., and Niazi, R. "Distribution network reconfiguration for power quality and reliability improvement using genetic algorithms", Int J Elec Power, 54(1), pp. 664-671 (2014).

20. Abazari, S. and Heidari Soudejani, M. "A new technique for efficient reconfiguration of distribution networks", Sci Iran, 22(6), pp. 2516-2526 (2015).

21. Farahani, V., Vahidi, B., and Askarian Abyaneh, H. "Reconfiguration and capacitor placement simultaneously for energy loss reduction based on an improved reconfiguration method", IEEE T Power Syst, 27(2), pp. 587-595 (2012).

22. Zhao, J., Li, X., Hao, J., et al. "Reactive power control of wind farm made up with doubly fed induction generators in distribution system", Electr Pow Syst Res, 80(1), pp. 698-706 (2010).

23. Srinivasa Rao, R., Ravindra, K., Satish, K., et al. "Power loss minimization in distribution system using network reconfiguration in the presence of distributed generation", IEEE T Power Syst, 28(1), pp. 317-325 (2013).

24. Chakravorty, M. and Das, D. "Voltage stability analysis of radial distribution networks", Int J Elec Power, 23(2), pp. 129-135 (2001).

25. Jashfar, S., Hosseini-Biyouki, M.M., and Esmaeili, S. "A stochastic programming to volt/var/total harmonic distortion control in distribution networks including wind turbines", Electr Pow Compo Sys, 43(7), pp. 733-746 (2015).

\section{Biographies}

Gholamreza Memarzadeh was born in Rafsanjan, Iran, 1990. He received the BSc degree in Power Electrical Engineering from Shahid Bahonar University, Kerman, Iran, 2012 and the MSc degree in Power Electrical Engineering from Shahid Bahonar University, Kerman, Iran, 2015. His main fields of research include voltage and reactive power control, distribution system analysis and optimization, and distribution network reconfiguration.

Saeid Esmaeili was born in Rafsanjan, Iran, 1976. $\mathrm{He}$ received the BSc degree in Power Electrical Engineering from K.N. Toosi University of Technology, Tehran, Iran, 1999 and the MSc degree in the same field from Iran University of Science and Technology, Tehran, Iran, 2002. He also received the PhD degree in Electrical Engineering from Amirkabir University of Technology, Tehran, Iran, 2007. He is currently an Associate Professor at the Department of Electrical Engineering at the Shahid Bahonar University of Kerman, Kerman, Iran. His research interests include analysis and optimization of electrical power system, power quality, and dynamics of electrical power system. 